\title{
Coverage-Controlled Polymorphism of H-Bonded Networks on $\mathrm{Au}(111)$
}

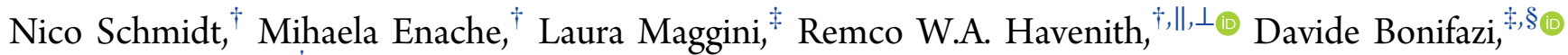 \\ and Meike Stöhr* ${ }^{*} \oplus \circ$ \\ ${ }^{\dagger}$ Zernike Institute for Advanced Materials and "Stratingh Institute for Chemistry, University of Groningen, Groningen 9747 AG, \\ The Netherlands \\ ${ }^{\ddagger}$ Namur Research College (NARC), University of Namur (UNamur), Rue de Bruxelles 61, 5000 Namur, Belgium \\ ${ }^{\S}$ School of Chemistry, Cardiff University, Park Place, Cardiff CF10 3AT, U.K. \\ ${ }^{\perp}$ Ghent Quantum Chemistry Group, University of Ghent, Gent 9000, Belgium
}

Supporting Information

ABSTRACT: We report on the self-assembly of a conformational flexible organic compound on $\mathrm{Au}(111)$ using scanning tunneling microscopy and low-energy electron diffraction measurements. We observed different conformers of the compound upon adsorption on the reconstructed $\mathrm{Au}(111)$ surface. Increasing the molecular coverage enhanced the lateral pressure, that is, parallel to the surface, favoring a coverage-controlled transition from a supramolecular network displaying only one molecular organization, into a polymorphic array with two coexisting arrangements. Our results give insights into the role of substrate-induced conformational changes on the formation of polymorphic supramolecular networks.

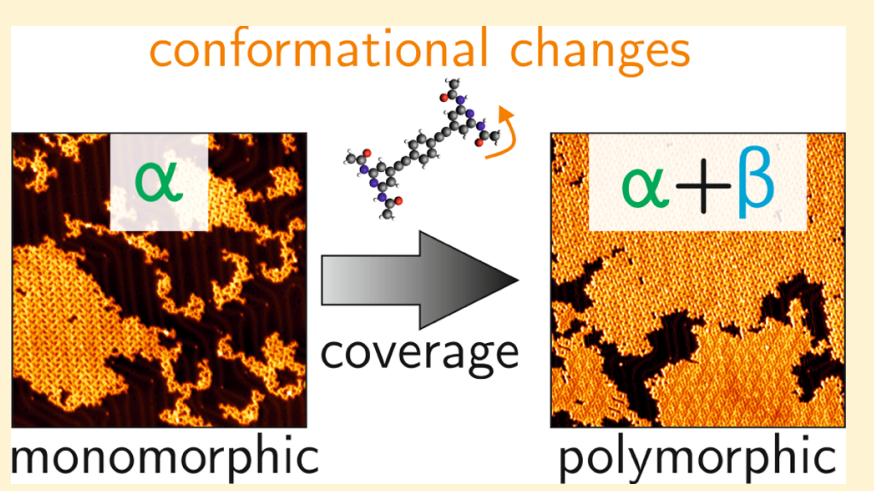

\section{INTRODUCTION}

Two-dimensional (2D) self-assembly of molecules on surfaces has been widely employed to fabricate functional, supramolecular networks in a bottom-up fashion. ${ }^{1-3}$ Steering the self-assembly toward a programmed supramolecular structure is often done through careful selection of the functional end groups of the molecular building blocks, and its control is very important if one wants to achieve functional properties both as $2 \mathrm{D}$ or three-dimensional functional materials. ${ }^{4-11}$ However, surface-confined molecular assemblies can exhibit an energetic equivalence of different structures, leading to polymorphism, that is, the simultaneous presence of different isoenergetic arrangements for the same compound. Transitions between those arrangements can be promoted, inter alia, by altering the number of substituents for the molecular compound, ${ }^{12}$ adsorbing the same compound on a different substrate, ${ }^{13,14}$ providing energy by means of annealing of the sample, ${ }^{15,16}$ varying the molecular coverage, ${ }^{17-20}$ or a combination of these factors. $^{21-23}$

In this study, we report on the coverage-controlled selfassembly of a linear molecule on $\mathrm{Au}(111)$. For the formation of well- and long-range-ordered structures, we deployed molecular recognition based on $\mathrm{H}$-bonding between substituted functional groups. For this purpose, H-bonding is commonly used because of its versatility, selectivity, directionality, and possibility of engineering complementary recognition motifs. $^{24,25}$ Linear molecule $\mathbf{1}$ used in our study bears two terminal 2,6-di(acetylamino)pyridyl (DAP) recognition sites linked via a central 1,4-diethynyl benzene (Scheme 1a). Although the trans conformation for the amide functional groups (Scheme $1 \mathrm{~b}$ ) is the most stable in the gas phase, ${ }^{26}$ other conformations can be however observed when adsorbed on the surface. When all amides are in trans conformation, the moiety can form triple $\mathrm{H}$-bonds with suitable uracyl partners

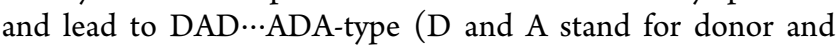
acceptor, respectively) $\mathrm{H}$-bonded heterodimeric arrays. However, when one or both amides are frontal-trans conformation, homodimerization is possible through the formation of quadruple $\mathrm{H}$-bonded dimers (DADA) ${ }_{2}$ and (ADADA $)_{2}{ }^{27,28}$ However, when the DAP is folded in a frontal-cis conformation, no dimers can be formed and these conformations are usually the most unstable because of steric clashes and electrostatic repulsions.

The conformational flexibility of the DAP moiety has allowed the successful formation of various self-assembled structures on the surface $e^{29-31}$ and, at that time, the first trimeric supramolecular heterocomplexes on $\operatorname{Ag}(111)$ under ultrahigh vacuum (UHV) conditions. ${ }^{32}$ At the solid-liquid

Received: December 20, 2018

Revised: March 1, 2019

Published: March 4, 2019 
Scheme 1. (a) Chemical Structure of 1, in Which a Central 1,4-Diethynyl Benzene Connects Two Terminal DAP Recognition Sites; (b) Conformational Equilibria Involving the Amide Functional Groups ${ }^{a}$

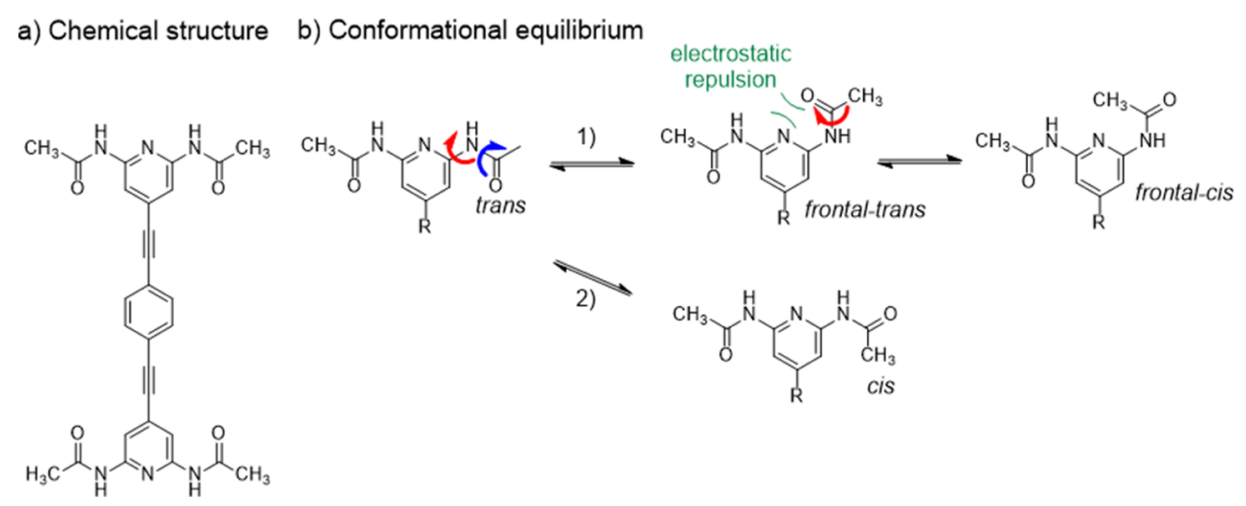

${ }^{a_{\text {The }}}$ thermodynamically most stable conformation in solution and gas phase is that of the trans amide. Other conformations are possible, such as the cis (see previous studies), ${ }^{26}$ frontal-trans, and frontal-cis. The curly arrows indicate the bonds around which rotations can take place.

interface, molecule 1 enabled the engineering of tricomponent nanopolygons and porous networks. ${ }^{33,34}$

Herein, we observed conformational changes upon adsorption on the $\mathrm{Au}(111)$ surface as a result of the conformational dynamicity. Moreover, the presence of different conformers allowed the formation of two isoenergetic supramolecular arrangements. Intriguingly, no complete conversion from one arrangement into the other could be achieved. Instead, by controlling the molecular coverage, we were able to transform the monomorphic network expressing one arrangement into a polymorphic assembly, expressing two coexisting molecular arrangements. The observed behavior and arrangements on $\mathrm{Au}(111)$ were considerably different from those of the same compound on $\operatorname{Ag}(111)$ at elevated temperatures, as the frontal-cis conformer was formed this time and a polymorphic arrangement is observed. ${ }^{31}$

\section{METHODS}

2.1. Sample Preparation. We prepared $\mathrm{Au}(111)$ by repeated cycles of sputtering with $\mathrm{Ar}^{+}$ions and subsequent annealing at $800 \mathrm{~K}$ under UHV conditions. Molecules were prepared following the literature procedure ${ }^{32}$ and sublimed at $490 \mathrm{~K}$ onto the sample using a Knudsen cell evaporator (home-built). During deposition, the sample was kept at room temperature (RT). Some samples were annealed after molecule deposition, which will be explicitly indicated throughout the text. We define one monolayer (ML) as the coverage for which the substrate is fully covered by molecules in the densest possible arrangement.

2.2. Scanning Tunneling Microscopy and Low-Energy Electron Diffraction Measurements. We performed our experiments in a UHV system with two chambers. The first chamber hosted a low-temperature scanning tunneling microscopy (STM) setup (Scienta Omicron GmbH) and had a base pressure of $<5 \times 10^{-11} \mathrm{mbar}$. The second chamber had a base pressure of $<1 \times 10^{-10}$ mbar and was equipped with a multichannel plate low-energy electron diffraction (LEED) system (Scienta Omicron $\mathrm{GmbH}$ ) as well as the Knudsen cell evaporator. The samples were at RT for LEED measurements, whereas STM measurements were performed at $77 \mathrm{~K}$. We used tips made from mechanically cut $\mathrm{Pt} / \mathrm{Ir}$ wire to obtain STM images in constant current mode. All voltages are given with respect to a grounded tip. We processed the STM images using the software WSxM. ${ }^{35}$

\section{RESULTS AND DISCUSSION}

3.1. Molecular Arrangements of 1 on $\mathrm{Au}(111)$. Figure 1a depicts an STM image of the self-assembly of 1 on $\mathrm{Au}(111)$ for a coverage below 0.5 ML. The sample was measured directly after molecule deposition, that is, without any annealing. We observed no long-range order. Molecules

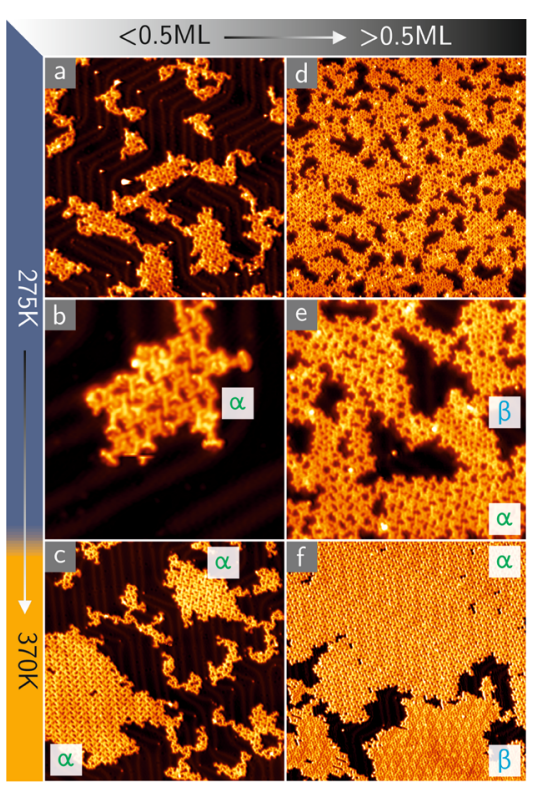

Figure 1. Self-assembly of $\mathbf{1}$ on $\mathrm{Au}(111)$ in dependence of molecular coverage and annealing temperature. (a) STM image for a coverage below $0.5 \mathrm{ML}\left(80 \times 80 \mathrm{~nm}^{2},-1.5 \mathrm{~V}\right.$, and $\left.30 \mathrm{pA}\right)$. The sample was prepared without annealing after deposition at RT. (b) Highresolution STM image $\left(20 \times 20 \mathrm{~nm}^{2},-0.6 \mathrm{~V}\right.$, and $\left.80 \mathrm{pA}\right)$ of the same sample shown in (a). For coverages below 0.5 ML, the molecular arrangement $\boldsymbol{\alpha}$ was exclusively present. (c) STM image of the sample shown in $(\mathrm{a}, \mathrm{b})$ after annealing at $370 \mathrm{~K}\left(80 \times 80 \mathrm{~nm}^{2}, 1.2\right.$ $\mathrm{V}$, and $20 \mathrm{pA}$ ). Compared to (a), the island size is significantly increased $\left(80 \times 80 \mathrm{~nm}^{2}, 1.2 \mathrm{~V}\right.$, and $\left.20 \mathrm{pA}\right)$. We still only observed arrangement $\boldsymbol{\alpha}$. (d) STM image for close to 1 ML coverage prepared without annealing $\left(100 \times 100 \mathrm{~nm}^{2}, 0.4 \mathrm{~V}\right.$, and $\left.80 \mathrm{pA}\right)$. (e) Highresolution STM image $\left(40 \times 40 \mathrm{~nm}^{2},-1.2 \mathrm{~V}\right.$, and $\left.20 \mathrm{pA}\right)$ of the same sample shown in (d). For coverages above 0.5 ML, the molecular arrangements $\boldsymbol{\alpha}$ and $\boldsymbol{\beta}$ were observed. (f) STM image of a sample similar to $(\mathrm{d}, \mathrm{e})$ after annealing at $370 \mathrm{~K}\left(100 \times 100 \mathrm{~nm}^{2}, 1.0 \mathrm{~V}\right.$, and $20 \mathrm{pA}$ ). For both arrangements, the island size increased. 
arranged into small patches that seemed to nucleate at the elbow sites of the $\mathrm{Au}(111)$ reconstruction. A high-resolution STM image of the same sample (Figure $1 \mathrm{~b}$ ) reveals that molecules assembled in only one arrangement, labeled as $\boldsymbol{\alpha}$. Annealing the same sample to $370 \mathrm{~K}$ yielded an increased longrange order, that is, larger islands of molecules were present (Figure 1c). Notably, we still observed arrangement $\boldsymbol{\alpha}$ exclusively.

Figure 1d shows an STM image of a sample with coverage close to $1 \mathrm{ML}$ before annealing, and no long-range order was observed. In contrast to the sample with low coverage (Figure 1a), we found different arrangements. In addition to arrangement $\boldsymbol{\alpha}$, a high-resolution STM image shows a second network, labeled $\boldsymbol{\beta}$ (Figure 1e). Annealing to $370 \mathrm{~K}$ again induced long-range order (Figure 1f). Both arrangements $\boldsymbol{\alpha}$ and $\boldsymbol{\beta}$ coexisted on the surface and showed increased island sizes when compared to the unannealed samples (Figure 1d). Independent of coverage or temperature, the unmodified herringbone pattern of the reconstructed $22 \times \sqrt{3}-\mathrm{Au}(111)$ surface $^{36}$ can be seen through the arrangement.

Figure 2a shows a high-resolution STM image of arrangement $\boldsymbol{\alpha}$. The rectangular unit cell is drawn in green, and a model of one molecule is overlaid to guide the eye. The principal directions of the Au surface are indicated by black
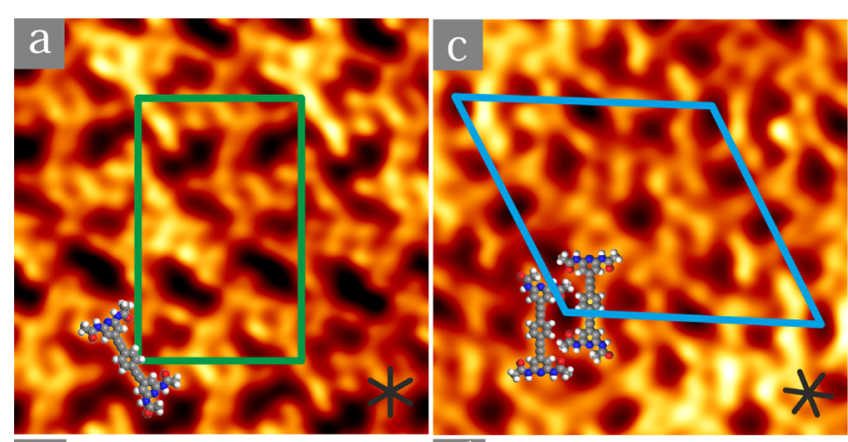

$\mathrm{b}$
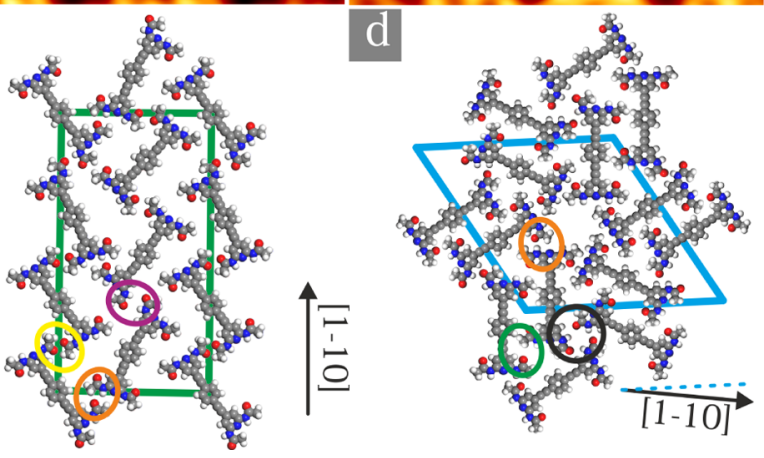

Figure 2. Comparison of the molecular arrangements $\boldsymbol{\alpha}$ and $\boldsymbol{\beta}$. (a) High-resolution STM image of molecular arrangement $\boldsymbol{\alpha}\left(8 \times 8 \mathrm{~nm}^{2}\right.$, $0.1 \mathrm{~V}$, and $170 \mathrm{pA}$ ). The black lines indicate the principal directions of the $\mathrm{Au}(111)$ substrate. The unit cell is shown in green. A molecular model of $\mathbf{1}$ is overlaid to guide the eye. (b) Tentative structural model of arrangement $\boldsymbol{\alpha}$. The long axis of the unit cell aligns with the [1 $\overline{1} 0]$ direction of the $\mathrm{Au}(111)$ substrate. The arrangement is stabilized by different $\mathrm{H}$-bonding interactions (marked by orange, yellow, and magenta circles). (c) High-resolution STM image of molecular arrangement $\boldsymbol{\beta}\left(7 \times 7 \mathrm{~nm}^{2}, 0.1 \mathrm{~V}\right.$, and $\left.170 \mathrm{pA}\right)$. The unit cell is shown in cyan. (d) Tentative structural model of arrangement $\boldsymbol{\beta}$. The arrangement is stabilized by a combination of single (marked by green circles), double (marked by orange circles), and cyclic trimeric $\mathrm{H}$ bonds involving three molecules (marked by a black circle). The unit cell is rotated by $\gamma= \pm 8^{\circ}$ with respect to the $[1 \overline{1} 0] \mathrm{Au}$ direction. lines in Figure 2a. The length of the unit cell vectors are $a=5.0$ $\mathrm{nm}$ and $b=3.0 \mathrm{~nm}$, and the angle is $\Theta=90^{\circ}$. The unit cell contains six molecules, which results in a molecular density of 0.40 molecules $/ \mathrm{nm}^{2}$. The long axis of the unit cell is furthermore parallel to the $[1 \overline{1} 0]$ direction of the $\mathrm{Au}(111)$ surface as shown in the tentative structural model (Figure $2 \mathrm{~b}$ ). We observed both trans and frontal-cis conformations which can be identified due to the different opening angles of the DAP site of 1 resulting in a different fingerprint in the STM images. Specifically, four molecules showed a combination of trans and frontal-cis, and the other two had all amides in the trans conformation. Figure $3 a-c$ shows a set of high-resolution STM images of the different conformations of $\mathbf{1}$ found in arrangement $\boldsymbol{\alpha}$. Additionally, we observed the molecular backbone bent for most of the molecules in the unit cell, that is, a distortion of the acetylene linkers resulting in a deviation of the C‥C bond angle from the common $180^{\circ}$. Similar bond isomers have also been observed for ethynylbearing porphyrins. ${ }^{37}$ Arrangement $\boldsymbol{\alpha}$ is stabilized by double $\mathrm{H}$-bonding interactions (marked orange, yellow, and magenta in Figure 2b).

Figure $2 c$ shows a high-resolution STM image of arrangement $\boldsymbol{\beta}$. The rhombic unit cell is displayed in cyan, and a pair of molecules is overlaid to guide the eye. We measured $a=b=$ $4.0 \mathrm{~nm}$ for the length of the unit cell vectors and an angle of $\Theta$ $=120^{\circ}$. The unit cell again contains six molecules, leading to a molecular density of 0.44 molecules $/ \mathrm{nm}^{2}$. The unit cell is slightly rotated by $\gamma= \pm 8^{\circ}$ with respect to the $[1 \overline{1} 0]$ direction of the $\mathrm{Au}(111)$ surface (Figure 2d). All six molecules in the unit cell exhibit a combination of trans and frontal-cis conformations of their $\mathrm{H}$-bonding recognition sites. A highresolution STM image of this combination of conformations is shown in Figure 3a,c. We did not observe any bending of the molecular backbone. Arrangement $\boldsymbol{\beta}$ is stabilized with a combination of different H-bonding motifs. For each molecule, one DAP unit, for which the amides are in the trans conformation, binds to three neighboring molecules in the following fashion: two times via double H-bonding (marked orange) and one time via a single $\mathrm{H}$-bond (marked green). The other DAP unit, for which one amide is in the trans conformation and the other one is in the frontal-cis conformation, also engages in H-bonding with three other molecules. However, it does so via a cyclic trimeric motif with two neighboring molecules (marked black) and a single $\mathrm{H}$ bond with another neighboring molecule (marked green). A summary of the properties of arrangements $\boldsymbol{\alpha}$ and $\boldsymbol{\beta}$ is shown in Table S1.

We gained complementary insight into the arrangements of 1 on $\mathrm{Au}(111)$ using LEED. Figure 4a shows a LEED pattern for a sample with close to $1 \mathrm{ML}$ coverage after annealing it at $370 \mathrm{~K}$ for $30 \mathrm{~min}$. We observed clear diffraction spots for several orders of diffraction. Figure $4 \mathrm{~b}, \mathrm{c}$ shows the simulated LEED pattern of arrangements $\boldsymbol{\alpha}$ and $\boldsymbol{\beta}$, respectively. Combining and overlaying these onto the measured LEED pattern (Figure 4d) results in a good agreement. The LEED data corroborate the observations made in STM: (i) arrangement $\boldsymbol{\beta}$ exhibits indeed a rotation of $\gamma= \pm 8^{\circ}$ with respect to the $[1 \overline{1} 0]$ Au direction and (ii) the good long-range order of both molecular structures after annealing.

Up to this point, we observed arrangement $\boldsymbol{\alpha}$ exclusively at coverages below $0.5 \mathrm{ML}$, whereas at higher coverages, arrangements $\boldsymbol{\alpha}$ and $\boldsymbol{\beta}$ coexisted. We saw that annealing the sample at $370 \mathrm{~K}$ had no influence on this polymorphism and 


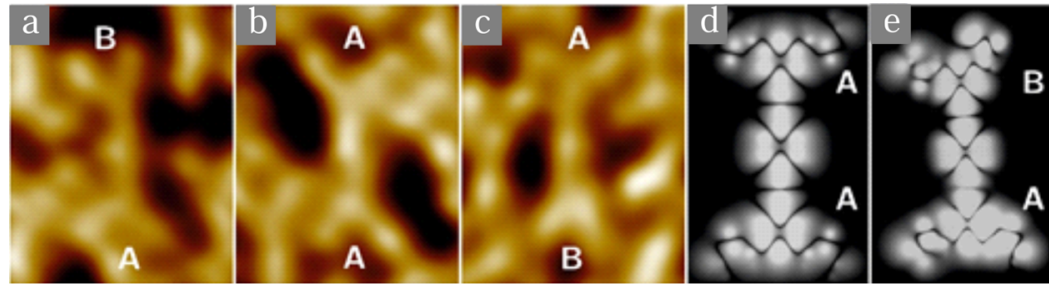

Figure 3. High-resolution STM images for different conformations of $1\left(2.4 \times 3.0 \mathrm{~nm}^{2}, 0.1 \mathrm{~V}\right.$, and $\left.170 \mathrm{pA}\right)$. The trans conformation of both amides in the DAP moiety is labeled $\mathbf{A}$, whereas the presence of the frontal-cis and trans conformation for the amides in the DAP moiety is labeled $\mathbf{B}$. In arrangement $\boldsymbol{\alpha}$, the molecules are in conformations $\mathbf{B}+\mathbf{A}(\mathrm{a}), \mathbf{A}+\mathbf{A}(\mathrm{b})$, and $\mathbf{A}+\mathbf{B}(\mathrm{c})$. In arrangement $\boldsymbol{\beta}$, all molecules are in conformation $\mathbf{A}+\mathbf{B}$ (d). Simulated STM images $(+1.3 \mathrm{~V})$ for a single molecule in conformations $\mathbf{A}+\mathbf{A}(\mathrm{d})$ and $\mathbf{B}+\mathbf{A}(\mathrm{e})$.
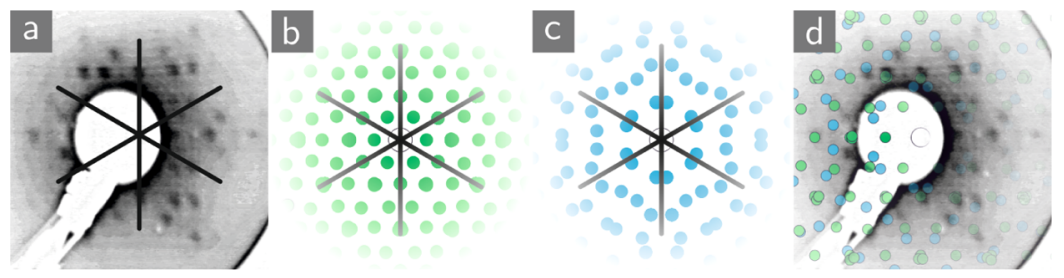

Figure 4. LEED pattern for molecular arrangements $\boldsymbol{\alpha}$ and $\boldsymbol{\beta}$. (a) LEED pattern for a coverage close to $1 \mathrm{ML}$ (11.5 eV). The black lines indicate the principal directions of the $\mathrm{Au}(111)$ substrate. Simulated LEED pattern of arrangements $\boldsymbol{\alpha}(\mathrm{b})$ and $\boldsymbol{\beta}(\mathrm{c})$. (d) Both simulated patterns combined and overlaid onto (a).

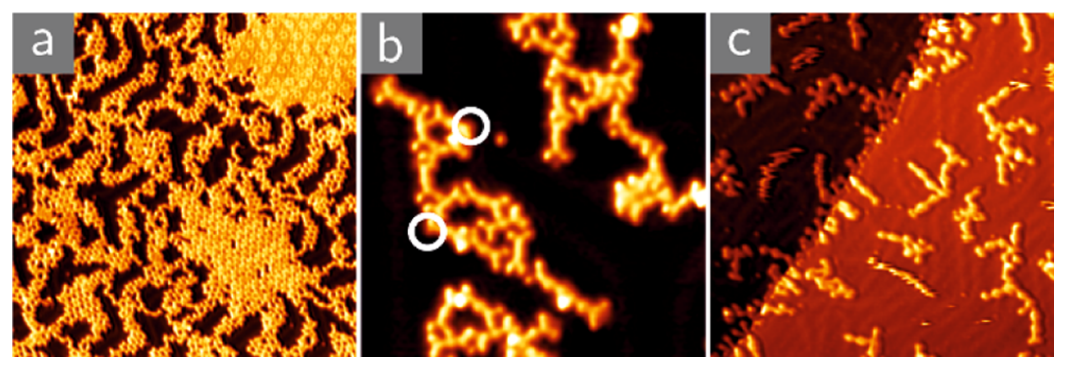

Figure 5. Self-assembly of 1 on $\mathrm{Au}(111)$ for post-deposition annealing above $370 \mathrm{~K}$. (a) STM image $\left(100 \times 100 \mathrm{~nm}^{2}, 1.0 \mathrm{~V}\right.$, and $\left.20 \mathrm{pA}\right)$ of a sample with close to $1 \mathrm{ML}$ coverage. The sample was annealed at $410 \mathrm{~K}$. The island size decreased and an increasing amount of molecules was found in disordered structures that followed the herringbone reconstruction of the $\mathrm{Au}(111)$ substrate. (b) High-resolution STM image $(18 \times 18$ $\mathrm{nm}^{2}, 1.0 \mathrm{~V}$, and $20 \mathrm{pA}$ ) for $<0.5 \mathrm{ML}$ coverage. The sample was annealed at $400 \mathrm{~K}$. An increasing amount of molecules exhibited defective recognition sites (white circles). (c) STM image of the same sample shown in (b) after additional annealing at $470 \mathrm{~K}\left(60 \times 60 \mathrm{~nm}^{2},-1.0 \mathrm{~V}\right.$, and 20 $\mathrm{pA})$. One-dimensional chains of molecules were observed.

only led to increased long-range order. Annealing samples above $400 \mathrm{~K}$ led to a decrease of island size coinciding with an increasing amount of disordered structures that followed the herringbone reconstruction as well as defective molecules (Figure 5a,b). After annealing at $470 \mathrm{~K}$, we observed onedimensional chains and decorated step edges (Figure 5c). We suggest that 1 decomposed at temperatures above $400 \mathrm{~K}$.

Additional to coverage and annealing, we also studied the influence of other sample preparation parameters. We therefore prepared samples with molecular deposition rates between 0.1 and $1 \mathrm{ML} / \mathrm{min}$. Furthermore, we varied the cooldown rate of the sample after annealing. This was achieved by either cooling the sample down to $77 \mathrm{~K}$ immediately after annealing or leaving it cooling down to RT first, followed by cooling down to $77 \mathrm{~K}$. We found no influence on the individual arrangements or their coexistence (Table 1). This suggests that the polymorphism of $\mathbf{1}$ is neither kinetically driven nor a result of quenching.

3.2. Discussion. We will discuss our findings in light of a previous study of molecule 1 on $\operatorname{Ag}(111)$. In this study, compound $\mathbf{1}$ formed a porous network stabilized by double $\mathrm{H}$ bonding upon deposition on the $\operatorname{Ag}(111)$ surface. $^{31}$ In this
Table 1. Varied Parameters and Their Influence on the Molecular Arrangements

\begin{tabular}{lll} 
& arrangement $\boldsymbol{\alpha}$ & arrangement $\boldsymbol{\beta}$ \\
$\begin{array}{l}\text { coverage } \\
\text { dependency }\end{array}$ & $\begin{array}{c}\text { no; visible for all } \\
\text { coverages }\end{array}$ & $\begin{array}{c}\text { yes; only observed above } \\
0.5 \mathrm{ML} \text { coverage }\end{array}$ \\
$\begin{array}{c}\text { temperature } \\
\text { dependency }\end{array}$ & no & no \\
$\begin{array}{c}\text { deposition rate } \\
\text { dependency }\end{array}$ & no & no \\
$\begin{array}{c}\text { cool-down rate } \\
\text { dependency }\end{array}$ & no & no \\
\hline
\end{tabular}

network, all amide functional groups were in the most stable trans conformation. Upon annealing, one amidic group rotated around the CO $\cdots$ NHR bond into a cis conformation (Scheme 1 and Scheme S1c), enabling quadruple H-bonding per binding DAP site. This resulted in a second, densely packed arrangement. Both arrangements were exclusively present and only dependent on the temperature. The results of this study contrast with the behavior of 1 on $\mathrm{Au}(111)$ in three aspects: (i) conformation of 1, (ii) temperature dependence, and (iii) coverage dependence. 
In contrast to 1 on $\operatorname{Ag}(111)$, we found conformational changes of 1 already upon adsorption on $\mathrm{Au}(111)$ at RT. Therefore, the reconstructed $\mathrm{Au}(111)$ surface seems to be instrumental in facilitating the conformational changes of $\mathbf{1}$. Although our calculations for adsorption of single molecules on $\mathrm{Au}(111)$ show that the trans conformation is energetically slightly favored in comparison to the frontal-cis one (Figure 6),

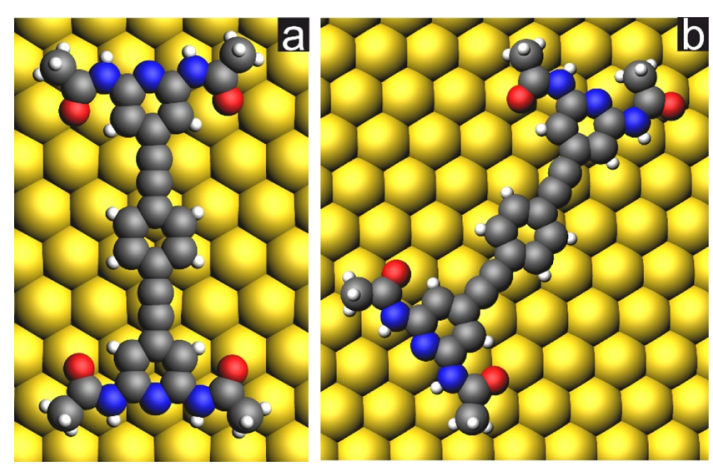

Figure 6. Optimized geometry for a single molecule adsorbed on the $\mathrm{Au}(111)$ surface in conformations (a) $\mathbf{A}+\mathbf{A}$ and (b) $\mathbf{B}+\mathbf{A}$. Conformation $\mathbf{A}+\mathbf{A}$ is energetically slightly more favorable (0.049 $\mathrm{eV}$ ) compared with conformation $\mathbf{B}+\mathbf{A}$.

we suggest that this energy penalty is overcome by the formation of intermolecular interactions that are established in the network. A similar conformational dependency on the underlying substrate has previously been observed for flexible substituents of a porphyrin derivative. ${ }^{38}$ Furthermore, relativistic effects have been shown to significantly influence the orbitals of $\mathrm{Au}$ atoms, resulting in the emergence of different self-assembly structures on $\mathrm{Au}(111)$ compared to $\mathrm{Ag}(111){ }^{39}$

Temperature can commonly be used to induce conformational changes of molecules resulting in a transformation of the molecular arrangement. ${ }^{15,16,40}$ For $\mathbf{1}$ on $\mathrm{Ag}(111)$, the conformational changes caused by annealing resulted in a transition from one arrangement to the other. ${ }^{31}$ This observation stands in contrast to the observations for $\mathbf{1}$ on $\mathrm{Au}(111)$. Annealing our samples only led to increased longrange order followed by decomposition of the compound at very elevated temperatures. We did not observe any influence of the temperature on either the conformation of $\mathbf{1}$ or the formation of arrangements $\boldsymbol{\alpha}$ or $\boldsymbol{\beta}$. Attempts to drive one arrangement into the other or possibly a different, third arrangement by means of temperature were also unsuccessful. We can infer from these observations that (i) the energy barrier between arrangements $\boldsymbol{\alpha}$ and $\boldsymbol{\beta}$ is higher than the energy needed for decomposition and (ii) no third arrangement exists that is thermodynamically favored and accessible. The first point is also supported by our transition-state calculations (Figure S1) which identify an energy barrier of $1.25 \mathrm{eV}$ between conformations $\mathbf{A}$ and $\mathbf{B}$. It should be noted however that a low-energy barrier combined with a significant energetic difference between $\boldsymbol{\alpha}$ and $\boldsymbol{\beta}$ could equally support our observation.

Coverage has often been reported to promote transitions between different structures of a polymorphic system. ${ }^{23,41-43}$ In cases of flexible molecules, this coverage-induced transition can go along with a conformational change of the molecules. ${ }^{44-46}$ Although no coverage dependence has been reported for 1 on $\operatorname{Ag}(111)$, increasing the lateral pressure by means of molecular coverage was the sole driving factor for observing polymorphism of $\mathbf{1}$ on $\mathrm{Au}(111)$. Arrangement $\boldsymbol{\beta}$ emerged for coverages above $0.5 \mathrm{ML}$. In contrast to arrangement $\boldsymbol{\alpha}$, molecules in arrangement $\boldsymbol{\beta}$ notably did not exhibit any bending. However, all molecules in arrangement $\boldsymbol{\beta}$ featured a conformational change, that is, exhibited amides both in their trans and frontal-cis conformations. Although this is certainly associated with an energy penalty, arrangement $\boldsymbol{\beta}$ exhibited an increased density, thus minimizing the surface free energy more efficiently than the less dense arrangement $\boldsymbol{\alpha}$. We furthermore were unable to achieve a complete transition from arrangement $\boldsymbol{\alpha}$ into arrangement $\boldsymbol{\beta}$. Instead, both arrangements coexisted above the threshold coverage of $0.5 \mathrm{ML}$ and furthermore grew in a uniform fashion until $1 \mathrm{ML}$ was reached, that is, at all time, arrangement $\boldsymbol{\alpha}$ was dominant.

\section{CONCLUSIONS}

In conclusion, we studied the self-assembly of a linear molecule with conformational flexible $\mathrm{H}$-bonding recognition sites on $\mathrm{Au}(111)$. We observed conformational changes upon adsorption on the reconstructed $\mathrm{Au}(111)$ surface. By controlling the coverage, we were able to transform a monomorphic array expressing one molecular arrangement into a polymorphic system with two coexisting molecular arrangements. The polymorphism itself was unaffected by variation of other preparation parameters including temperature, making the molecular coverage the sole driving force of the mono- to polymorphic transition. These results stand in contrast to previous findings for the same molecule on $\operatorname{Ag}(111)$, for which a net transition between two molecular organizations was observed. Our findings not only illustrate the role of conformational changes in polymorphic supramolecular networks but also showcase how molecules with high conformational flexibility can be used to achieve different self-assembled architectures on structurally similar surfaces.

\section{ASSOCIATED CONTENT}

\section{Supporting Information}

The Supporting Information is available free of charge on the ACS Publications website at DOI: 10.1021/acs.jpcc.8b12260.

Properties of molecular arrangements $\boldsymbol{\alpha}$ and $\boldsymbol{\beta}$; different conformations of the recognition site of $\mathbf{1}$; transition path for a single molecule in gas phase from conformation $\mathbf{A}+\mathbf{A}$ to conformation $\mathbf{B}+\mathbf{A}$; optimized geometry of a single molecule in gas phase in conformations $\mathbf{A}+\mathbf{A}$ and $\mathbf{B}+\mathbf{A}$; high-resolution STM images of molecular arrangement $\boldsymbol{\alpha}$; computational details. (PDF)

\section{AUTHOR INFORMATION}

\section{Corresponding Author}

*E-mail: m.a.stohr@rug.nl.

ORCID $\odot$

Remco W.A. Havenith: 0000-0003-0038-6030

Davide Bonifazi: 0000-0001-5717-0121

Meike Stöhr: 0000-0002-1478-6118

\section{Author Contributions}

The manuscript was written through contributions of all authors. All authors have given approval to the final version of the manuscript.

Notes

The authors declare no competing financial interest. 


\section{ACKNOWLEDGMENTS}

This work was supported by the Netherlands Organisation for Scientific Research (NWO) (Vidi grant 723.014.008), by the European Research Council (ERC-2012-StG 307760-SURFPRO), and by the Zernike Institute for Advanced Materials of the University of Groningen. D.B. thanks Cardiff University for the support. We would like to thank the Center for Information Technology of the University of Groningen for their support and for providing access to the Peregrine highperformance computing cluster. We would like to thank the Berendsen Center for Multiscale Modeling and Material Design and the Zernike Institute for Advanced Materials at the University of Groningen for their support and for providing access to the Nieuwport high-performance computing cluster.

\section{REFERENCES}

(1) Whitesides, G.; Mathias, J.; Seto, C. Molecular self-assembly and nanochemistry: a chemical strategy for the synthesis of nanostructures. Science 1991, 254, 1312-1319.

(2) Barth, J. V.; Costantini, G.; Kern, K. Engineering Atomic and Molecular Nanostructures at Surfaces. Nature 2005, 437, 671-679.

(3) De Feyter, S.; De Schryver, F. C. Two-Dimensional Supramolecular Self-Assembly Probed by Scanning Tunneling Microscopy. Chem. Soc. Rev. 2003, 32, 139-150.

(4) Yan, Q.; Luo, Z.; Cai, K.; Ma, Y.; Zhao, D. Chemical Designs of Functional Photoactive Molecular Assemblies. Chem. Soc. Rev. 2014, 43, 4199-4221.

(5) Puigmartí-Luis, J.; Pérez del Pino, Á.; Laukhina, E.; Esquena, J.; Laukhin, V.; Rovira, C.; Vidal-Gancedo, J.; Kanaras, A. G.; Nichols, R J.; Brust, M.; et al. Shaping Supramolecular Nanofibers with Nanoparticles Forming Complementary Hydrogen Bonds. Angew. Chem. Int. Ed. 2008, 47, 1861-1865.

(6) Praveen, V. K.; Ranjith, C.; Bandini, E.; Ajayaghosh, A.; Armaroli, N. Oligo(Phenylenevinylene) Hybrids and Self-Assemblies: Versatile Materials for Excitation Energy Transfer. Chem. Soc. Rev. 2014, 43, 4222-4242.

(7) Pinalli, R.; Dalcanale, E.; Ugozzoli, F.; Massera, C. Resorcinarene-Based Cavitands as Building Blocks for Crystal Engineering. CrystEngComm 2016, 18, 5788-5802.

(8) Bordević, L.; Marangoni, T.; Miletić, T.; Rubio-Magnieto, J.; Mohanraj, J.; Amenitsch, H.; Pasini, D.; Liaros, N.; Couris, S.; Armaroli, N.; et al. Solvent Molding of Organic Morphologies Made of Supramolecular Chiral Polymers. J. Am. Chem. Soc. 2015, 137, $8150-8160$.

(9) Elacqua, E.; Lye, D. S.; Weck, M. Engineering Orthogonality in Supramolecular Polymers: From Simple Scaffolds to Complex Materials. Acc. Chem. Res. 2014, 47, 2405-2416.

(10) Bonifazi, D.; Mohnani, S.; Llanes-Pallas, A. Supramolecular Chemistry at Interfaces: Molecular Recognition on Nanopatterned Porous Surfaces. Chem.-Eur. J. 2009, 15, 7004-7025.

(11) Babu, S. S.; Prasanthkumar, S.; Ajayaghosh, A. Self-Assembled Gelators for Organic Electronics. Angew. Chem. Int. Ed. 2012, 51, $1766-1776$

(12) Yokoyama, T.; Yokoyama, S.; Kamikado, T.; Okuno, Y.; Mashiko, S. Selective Assembly on a Surface of Supramolecular Aggregates with Controlled Size and Shape. Nature 2001, 413, 619621.

(13) Klappenberger, F.; Cañas-Ventura, M. E.; Clair, S.; Pons, S.; Schlickum, U.; Qu, Z.-R.; Strunskus, T.; Comisso, A.; Wöll, C.; Brune, $\mathrm{H}$.; et al. Does the Surface Matter? Hydrogen-Bonded Chain Formation of an Oxalic Amide Derivative in a Two- and ThreeDimensional Environment. ChemPhysChem 2008, 9, 2522-2530.

(14) Müller, K.; Moreno-Lõpez, J. C.; Gottardi, S.; Meinhardt, U.; Yildirim, H.; Kara, A.; Kivala, M.; Stöhr, M. Cyano-Functionalized Triarylamines on Coinage Metal Surfaces: Interplay of Intermolecular and Molecule-Substrate Interactions. Chem.-Eur. J. 2016, 22, 581589.
(15) Klappenberger, F.; Cañas-Ventura, M. E.; Clair, S.; Pons, S.; Schlickum, U.; Qu, Z.-R.; Brune, H.; Kern, K.; Strunskus, T.; Wöll, C.; et al. Conformational Adaptation in Supramolecular Assembly on Surfaces. ChemPhysChem 2007, 8, 1782-1786.

(16) Ueji, K.; Jung, J.; Oh, J.; Miyamura, K.; Kim, Y. Thermally activated polymorphic transition from a $1 \mathrm{D}$ ribbon to a $2 \mathrm{D}$ carpet: squaric acid on $\mathrm{Au}(111)$. Chem Commun 2014, 50, 11230-11233.

(17) Buchner, F.; Comanici, K.; Jux, N.; Steinrück, H.-P.; Marbach, H. Polymorphism of Porphyrin Molecules on $\mathrm{Ag}(111)$ and How to Weave a Rigid Monolayer. J. Phys. Chem. C 2007, 111, 13531-13538.

(18) Ye, Y.; Sun, W.; Wang, Y.; Shao, X.; Xu, X.; Cheng, F.; Li, J.; Wu, K. A Unified Model: Self-Assembly of Trimesic Acid on Gold. J. Phys. Chem. C 2007, 111, 10138-10141.

(19) Eichhorn, J.; Schlögl, S.; Lotsch, B. V.; Schnick, W.; Heckl, W. M.; Lackinger, M. Self-Assembly of Melem on $\mathrm{Ag}(111)$-Emergence of Porous Structures Based on Amino-Heptazine Hydrogen Bonds. CrystEngComm 2011, 13, 5559.

(20) Gottardi, S.; Müller, K.; Moreno-Lõpez, J. C.; Yildirim, H.; Meinhardt, U.; Kivala, M.; Kara, A.; Stöhr, M. Cyano-Functionalized Triarylamines on $\mathrm{Au}(111)$ : Competing Intermolecular Versus Molecule/Substrate Interactions. Adv. Mater. Interfaces 2014, 1, 1300025 .

(21) Zhang, L.; Lepper, M.; Stark, M.; Menzel, T.; Lungerich, D.; Jux, N.; Hieringer, W.; Steinrück, H.-P.; Marbach, H. On the Critical Role of The Substrate: The Adsorption Behaviour of Tetrabenzoporphyrins on Different Metal Surfaces. Phys. Chem. Chem. Phys. 2017, 19, 20281-20289.

(22) Kühnle, A. Self-Assembly of Organic Molecules at Metal Surfaces. Curr. Opin. Colloid Interface Sci. 2009, 14, 157-168.

(23) Pivetta, M.; Blüm, M.-C.; Patthey, F.; Schneider, W.-D. Coverage-Dependent Self-Assembly of Rubrene Molecules on Noble Metal Surfaces Observed by Scanning Tunneling Microscopy. ChemPhysChem 2010, 11, 1558-1569.

(24) Steiner, T. The Hydrogen Bond in the Solid State. Angew. Chem. Int. Ed. 2002, 41, 49-76.

(25) Desiraju, G. R. Supramolecular Synthons in Crystal Engineering-A New Organic Synthesis. Angew Chem. Int. Ed. Engl. 1995, 34, 2311-2327.

(26) Katritzky, A. R.; Ghiviriga, I. An NMR study of the tantomerism of 2-acylaminopyridines. J. Chem. Soc., Perkin Trans. 2 1995, 1651-1653.

(27) Beijer, F. H.; Sijbesma, R. P.; Vekemans, J. A. J. M.; Meijer, E. W.; Kooijman, H.; Spek, A. L. Hydrogen-Bonded Complexes of Diaminopyridines and Diaminotriazines: Opposite Effect of Acylation on Complex Stabilities. J. Org. Chem. 1996, 61, 6371-6380.

(28) Sijbesma, R. P.; Meijer, E. W. Quadruple Hydrogen Bonded Systems. Chem. Commun. 2003, 5-16.

(29) Marangoni, T.; Bonifazi, D. Nano- and microstructuration of supramolecular materials driven by $\mathrm{H}$-bonded uracil-2,6-diamidopyridine complexes. Nanoscale 2013, 5, 8837.

(30) Palma, C.-A.; Ciesielski, A.; Öner, M. A.; Schaeffer, G.; Lehn, J.M.; Barth, J. V.; Samorì, P. Two-Dimensional Soft Supramolecular Networks. Chem. Commun. 2015, 51, 17297-17300.

(31) Matena, M.; Llanes-Pallas, A.; Enache, M.; Jung, T.; Wouters, J.; Champagne, B.; Stöhr, M.; Bonifazi, D. Conformation-Controlled Networking of H-Bonded Assemblies on Surfaces. Chem. Commun. 2009, 3525-3527.

(32) Llanes-Pallas, A.; Matena, M.; Jung, T.; Prato, M.; Stöhr, M.; Bonifazi, D. Trimodular Engineering of Linear Supramolecular Miniatures on $\operatorname{Ag}(111)$ Surfaces Controlled by Complementary Triple Hydrogen Bonds. Angew. Chem. Int. Ed. 2008, 47, 7726-7730.

(33) Llanes-Pallas, A.; Palma, C.-A.; Piot, L.; Belbakra, A.; Listorti, A.; Prato, M.; Samorì, P.; Armaroli, N.; Bonifazi, D. Engineering of Supramolecular H-Bonded Nanopolygons via Self-Assembly of Programmed Molecular Modules. J. Am. Chem. Soc. 2009, 131, 509-520.

(34) Palma, C.-A.; Bonini, M.; Llanes-Pallas, A.; Breiner, T.; Prato, M.; Bonifazi, D.; Samorì, P. Pre-Programmed Bicomponent Porous 
Networks at the Solid-Liquid Interface: The Low Concentration Regime. Chem. Commun. 2008, 5289-5291.

(35) Horcas, I.; Fernández, R.; Gómez-Rodríguez, J. M.; Colchero, J.; Gómez-Herrero, J.; Baro, A. M. WSXM: A Software for Scanning Probe Microscopy and a Tool for Nanotechnology. Rev. Sci. Instrum. 2007, 78, 013705.

(36) Barth, J. V.; Brune, H.; Ertl, G.; Behm, R. J. Scanning Tunneling Microscopy Observations on the Reconstructed $\mathrm{Au}(111)$ Surface: Atomic Structure, Long-Range Superstructure, Rotational Domains, and Surface Defects. Phys. Rev. B: Condens. Matter Mater. Phys. 1990, 42, 9307-9318.

(37) Fendt, L.-A.; Stöhr, M.; Wintjes, N.; Enache, M.; Jung, T. A.; Diederich, F. Modification of Supramolecular Binding Motifs Induced by Substrate Registry: Formation of Self-Assembled Macrocycles and Chain-Like Patterns. Chem.-Eur. J. 2009, 15, 11139-11150.

(38) Jung, T. A.; Schlittler, R. R.; Gimzewski, J. K. Conformational Identification of Individual Adsorbed Molecules with the STM. Nature 1997, 386, 696-698.

(39) Zhang, X.; Li, N.; Wang, H.; Yuan, C.; Gu, G.; Zhang, Y.; Nieckarz, D.; Szabelski, P.; Hou, S.; Teo, B. K.; et al. Influence of Relativistic Effects on Assembled Structures of V-Shaped Bispyridine Molecules on $\mathrm{M}(111)$ Surfaces Where $\mathrm{M}=\mathrm{Cu}, \mathrm{Ag}$, Au. ACS Nano 2017, 11, 8511-8518.

(40) Weigelt, S.; Busse, C.; Petersen, L.; Rauls, E.; Hammer, B.; Gothelf, K. V.; Besenbacher, F.; Linderoth, T. R. Chiral Switching by Spontaneous Conformational Change in Adsorbed Organic Molecules. Nat. Mater. 2006, 5, 112-117.

(41) Stöhr, M.; Wahl, M.; Galka, C. H.; Riehm, T.; Jung, T. A.; Gade, L. H. Controlling Molecular Assembly in Two Dimensions: The Concentration Dependence of Thermally Induced 2D Aggregation of Molecules on a Metal Surface. Angew. Chem. Int. Ed. 2005, 44, 7394-7398.

(42) Böhringer, M.; Morgenstern, K.; Schneider, W.-D.; Berndt, R. Two-Dimensional Self-Assembly of Magic Supramolecular Clusters. J. Phys. Condens. Matter 1999, 11, 9871-9878.

(43) Iacovita, C.; Fesser, P.; Vijayaraghavan, S.; Enache, M.; Stöhr, M.; Diederich, F.; Jung, T. A. Controlling the Dimensionality and Structure of Supramolecular Porphyrin Assemblies by Their Functional Substituents: Dimers, Chains, and Close-Packed 2D Assemblies. Chem.-Eur. J. 2012, 18, 14610-14613.

(44) Boom, K.; Stein, F.; Ernst, S.; Morgenstern, K. CoverageInduced Conformational Selectivity. J. Phys. Chem. C 2017, 121, 20254-20258.

(45) Enache, M.; Maggini, L.; Llanes-Pallas, A.; Jung, T. A.; Bonifazi, D.; Stöhr, M. Coverage-Dependent Disorder-to-Order Phase Transformation of a Uracil Derivative on $\mathrm{Ag}(111)$. J. Phys. Chem. C 2014, 118, 15286-15291.

(46) Samuely, T.; Liu, S.-X.; Wintjes, N.; Haas, M.; Decurtins, S.; Jung, T. A.; Stöhr, M. Two-Dimensional Multiphase Behavior Induced by Sterically Hindered Conformational Optimization of Phenoxy-Substituted Phthalocyanines. J. Phys. Chem. C 2008, 112, 6139-6144. 